\title{
Current Situation and Development of Green Building Rating System in Myanmar
}

\author{
May L win ${ }^{1}$, and Kriengsak Panuwatwanich ${ }^{1 *}$ \\ ${ }^{1}$ School of Civil Engineering and Technology, Sirindhorn International Institute of Technology, \\ Thammasat University, Pathum Thani, Thailand
}

\begin{abstract}
Since 2016 Myanmar has undergone political and economic reforms. A movement to develop the country with economic growth is a significant matter for the country. In M yanmar, the construction sector is a main driving force for the country's economy in terms of investments and job opportunities of citizens. Electricity used for the construction industry leads to the insufficient energy output of the country. M oreover, waste and pollution are inevitable as a result of Myanmar's economic growth. Green building development in M yanmar is in its initial stage but currently lacks governmental, or voluntary support to devise appropriate rules and regulations for green construction. In particular, the lack of awareness among developers, stakeholders, architects, engineers, contractors, employees and the public about green building has worsened the development progress. This paper reveals why green building development is needed in Myanmar and provides an overview of the current level of green growth in Myanmar. In addition, this paper compares widely used seven existing environmental assessment tools around the world - LEED, BREEA M, Green M ark, Green Star, Three Star - Chinese Green B uilding L abel-3, CA SBEE, and HQE as references for the development of green building rating tool with the view to identify aspects that are compatible with the local conditions of M yanmar.
\end{abstract}

Keywords: M yanmar, green building development, rating system, public awareness

\section{Introduction}

Myanmar is located in South East Asia and starts to transform from an isolated economy to a middle-income country. Myanmar is also a member of the United Nations and ASEAN as a country that craves development by opening the door for investments. Total country area is 677,000 Square kilometers which are covered by mountain ranges, rivers, and forests. Myanmar has over 60 million people and 135 ethnic groups [1].

*Corresponding author: kriengsak@ siit.tu.ac.th 
Myanmar experiences a rapid population increase and urbanization problem especially in Yangon, the largest city in the country. High rise buildings, luxury residences, condominiums, and affordable housing are booming in Yangon and the government aims to build 1 million homes for public requirements by 2030. Hence, foreign and local investors are encouraged to subsidize infrastructure such as housing, bridges, roads, and industrial zones with the aim of sustainable development and high quality. Myanmar is a place with abundant natural resources such as water, land, and minerals and a worthwhile place for foreign investments. However, new construction and infrastructures entail to be fueled by electricity, and energy demand is a current crisis for Myanmar which has no adequate energy output for the whole country. Clean and cost-effective energy is also a special need for residents. What is more, waste and pollution from forthcoming factories and buildings are other factors to consider for environmental protection. The government has not set standards and specifications to define a green building. Hence, it is difficult to recognize what constitutes a green building design and construction among engineers and architects in the construction industry [2]. Moreover, companies and government organizations have no experts for modern technology and less awareness about the role of engineers for environmental sustainability. Traditional construction method impacts on environment and society. Besides, city planning is a preferential issue which needs to be considered, for residential building construction due to waste management and drainage systems are not systematic in Myanmar at present [3]. Thus, green building design including energy efficiency, water efficiency, pollution reduction and indoor environmental quality is required for the construction industry.

Green building is a widely adopted construction technique around the world to build a sustainable city. It is also a method that can minimize natural resources depletion for building consumption, pollution from construction materials, environmental degradation, and increase the wellbeing of the occupants [4]. Moreover, the assessment tool, a green building standard for the whole cycle of a building, which recognizes whether a building meets green building objectives, is the first step in the implementation of green building practice in all countries. Besides, if there is awareness for green building, customer demand will rise and companies will be more interested in green construction that leads to green building development. Hence, public awareness about green buildings and certification systems that will be suitable for local conditions are needed at the initial stage of sustainable development in Myanmar.

\section{Factors Affecting Requirements of Green Buildings in Myanmar}

\subsection{Insufficient Current Energy Supply and Uncertainty for Future Energy Potential}

For Myanmar, as a developing country, inadequate energy supply is a major problem for modifying all kinds of sectors for economic development. The highest amount of electricity generation is a demand for future infrastructure development in Myanmar [5]. According to National Electrification Plan (NEP) by the World Bank and United Nations, energy production targets are at $50 \%$ by $2020,75 \%$ by 2025 and $100 \%$ by 2030 including renewable energy, 1/5 of total energy generation [5]. Although Myanmar has been going forward since 2016 by the policy of the new government for the energy sector, there is still an energy crisis and uncertainty for the future. While one-third of the country has access to energy supply, most areas of the country have not been connected to the national grid lines. Some rural areas use off-grid solar power and power generated by diesel [5]. Myanmar has the lowest rate of electricity generation around the world with $160 \mathrm{kWh}$ per capita consumption a year 
in 2014 and increases $263 \mathrm{kWh}$ in 2015/2016 which is $1 / 10$ of UK consumption [5]. The current installed capacity of the whole country is 4,422 MW in 2014 which is lower than Asian countries - 32,600 MW in Thailand and 26,300 MW in Vietnam [6]. In 2015-2016, 5,029 MW has been produced by the mixed-use energy system [2]. According to the Asia Development Bank, energy demand increases $15 \%$ yearly and it will be doubled by 2020 . Hydropower is applied mostly for electricity generation in Myanmar, but it is not possible to rely solely on it for the long term. Although coal is planned to be used for filling the gap of the Myanmar energy sector, local people are against the coal plant projects for the detrimental effect of green-house gas emissions. Myanmar is a country that possesses solar and wind power potential for renewable energy because of the geographical conditions of the country. However, energy generation potential is on an uncertain pathway with the lack of clear master plan and investments within the country.

\subsection{Limited Water Supply and Inadequate Waste Water Treatment}

Water resources sustainability is essential for all people around the world. In Myanmar, there are enormous sources for water usage but some areas are distant from resources and water supply connection system. In the largest city, Yangon, 135 million gallons of freshwater are supplied from Yangon City Development Committee every day and occupants consume over 200 million gallons a day. Thus, most people in extended urban areas depend on natural lakes, rivers, and tube wells [7]. Newly constructed high rise buildings in Yangon rely on 30 million gallons of water from tube wells daily because the current water supply of Yangon is unable to support water sufficiently. The more underground usage of water, the more dangerous the stability of buildings and some buildings constructed on soft soil are at risk of settlement in some townships [7]. Yangon, surrounded by the sea, will encounter saltwater intrusion if groundwater from tube wells is extracted too much. Saltwater intrusion will occur from the base when the freshwater at the upper layer is depleted. Yangon would not become a smart and sustainable city if groundwater sources face risky conditions. Hence, Myanmar needs to apply water resources effectively in the construction industry.

The rapid increase in population also leads to deterioration of the wastewater management system of the city. Wastewater from households and factories runs off to streams, lakes, and the river can be hazardous to the original water resource. According to Myanmar's conventional sewage system in cities, black water is stored in septic tanks and water is permeable into the soil after many years. Greywater from household flows to the surface drains without proper individual treatment and wastewater flooding can be occurred by blocking trash in the drain in the rainy season before reaching to main pipelines [8]. There are not enough treatment plants that connect to the main pipelines to discharge treated water to rivers. Moreover, waste from factories and other areas run to the streams and rivers directly without prior treatment [9]. This is the main reason affecting the health of residents from hazardous water sources. JICA has a plan for an upgraded system to link all waste lines and treatment plants from new areas of Yangon in greater Yangon project 2040. Consequently, water conservation and systematic wastewater treatment system, as part of the green building design is a necessity for the construction sector in Myanmar.

\subsection{Carbon dioxide Emissions and Climate Change}

Nowadays, climate change is a global issue and Myanmar cannot be separated from other countries that suffer from global warming, even though a vast amount of $\mathrm{CO} 2$ is not emitted as much as other industrialized countries. As a country moving forward for development, economic growth and environmental conservation need consideration in parallel. Approximately, 500 billion tons of $\mathrm{CO} 2$ have been released by burning fuel, gas, 
and oil from rapid population growth, increasing urbanization and the industrial revolution, and about half of emissions have been tracked in the atmosphere [10]. For Myanmar which has plans to put into the effort of energy necessity, this is an anxious issue for the future [3]. With economic development, energy consumption and greenhouse gas emission are great environmental challenges that will impact the prospects of a country [10]. Ancha Srinivasa, a principal climate change specialist at ADB remarks that Myanmar acquires to take an action of carbon reduction for climate change control when new investments are performed [11]. The massive amount of Green House Gas (GHG) emissions around the world can be a succeeding problem for vulnerable people to climate change from the lower part of Myanmar [11]. In the central region of Myanmar, drought, scarcity of water, and crop depletion can be in trouble with the livelihood of rural people. Rising sea level that results from soaring ocean temperature is the base of cyclone for people in coastal line and almost 140,000 of Myanmar residents were killed by cyclone Nargis in 2008 [11]. According to Myanmar's National Adaptation Programme of Action (NAPA) to climate change of 2012, it is predicted that the average temperature will rise from 0.8 to $1.4^{\circ} \mathrm{C}$ in 2050 . By comparison of the economic sector, building energy consumption is about $35 \%$ of the total and $\mathrm{CO} 2$ emission from buildings is almost $30 \%$ of the total as well in both developed and developing countries [10]. Hence, renewable energy technology should be applied in building performance to reduce energy consumption, and it will also help control the emission of $\mathrm{CO} 2$ and climate change adaptation [10].

\subsection{Solid Waste Management and Construction Industry}

In Yangon, environmental deterioration and health problems are mostly affected by the inadequate solid waste management system, like many cities in developing countries [12]. Households and industries produce around 1690 tons of waste daily and waste is collected by manpower and garbage truck supported by Yangon City Development Committee (YCDC). There are six waste disposal landfill sites in Yangon and one of them can generate electricity from biogas [8]. YCDC has not set planning for equipment and needs investment to improve solid waste service [12]. In the whole country, 5,616 tons of rubbish is produced daily and it is expected that waste increases 21,012 tons per day, 0.85 $\mathrm{kg} /$ capita/day by 2025 . Waste recycled volume and the number of the recycled industry has not yet been defined [9]. With the lack of measures to reduce the use of plastic bags and dumping biodegradable and non-biodegradable waste separately, systematic garbage dumping is not still practiced in Myanmar [12]. Moreover, the limitation of landfill sites within the city boundary has become considerable fact in correspondence with population growth [9]. Fifty percent of trash from the landfill site comes from buildings and households. Construction materials derive from different kinds of resources, and the reduction of construction waste is also a fact that needs to be examined. Regarding green building rating systems, waste management is one of the criteria and municipal waste collection will be effective if an individual waste management technique is utilized in buildings [13].

\section{Green Buildings Movement in Myanmar}

\subsection{Green Building Committee - Building Engineering Institute Myanmar}

Building Engineering Institute (BEI) was successfully established by the Myanmar Engineering Society (MES) and the Committee for Quality Control of High-Rise Building Construction Project (CQHP) on 23rd November 2014 in Yangon. Six committees are co-founded under BEI, including (1) Architecture, (2) Structure, (3) Geotechnical, 
(4) MEP (M\&E), (5) Construction, Quality Control \& Safety, and (6) Green Building. Objectives of this organization are to promote the building sector and technology and to enhance the welfare of society by linking all stakeholders from related engineering fields, to cooperate institutional organizations, industries, and the government, to complete codes, rules and regulations and references, and to contribute seminar, training, and conference for technical improvement [14].

\subsection{Green Building Chapter in Myanmar National Building Code}

The initial stage of Green Building Certification System of Myanmar has been introduced by representatives from the Green Building Committee, BEI as section 2.12 ARCHITECTURE FOR ENERGY EFFICIENCY AND GREEN in the Myanmar National Building Code 2016, which is the guideline for Myanmar Construction Industry. The purpose of this section is to provide green building criteria and basic requirements for energy-efficient building design in Myanmar. This chapter includes green building criteria of Myanmar, namely, "Energy" for saving energy usage in buildings, using low embodied energy materials, considering air circulation and natural lighting in building design, and utilizing renewable energy, "Water" to harvest rainwater, recycle greywater, and manage wastewater for water efficiency and water resources conservation, "Human Comfort and Health" to maintain the indoor temperature in the comfort zone for occupants, provide adequate lighting and good quality of air for occupants' health, and "Environmental Impact" including carbon emission reduction, enhancing greenery to reduce urban heat island effect, decreasing pollution, and landfill waste. This code is proposed for new construction, extension and retrofitting of commercial building types (excluding religious buildings, lowcost housings, and the public buildings by the government or other non-government organizations) of more than 100,000 sq. $\mathrm{ft}$ area within Yangon and other places similar to Yangon. It also demonstrates environmental sustainability standards by referencing International Green Construction Code (version 2) and green building design guide by Building and Construction Authority, Singapore. The specified building types must act in accordance with these standards. This code will develop unceasingly for the design and construction of green buildings in Myanmar in such a way that it creates building's performance of resource efficiency, occupants' wellbeing, and environmental reputation. In addition, climate change in Yangon is considered in this code to mitigate global warming. Green building engineering and technology which is appropriate to geographical conditions, climatic background and construction market of Myanmar is a requirement to carry on this proposed code for green building development in Myanmar [15].

\subsection{Green Building Construction in Myanmar}

According to the Myanmar Times article on 1st of May 2017, U Ye Htun Aung, managing director of Team 6 engineering solution and control Company, remarks that although the government has not set rules and regulations for green building, there are some buildings in Myanmar which are qualified under the certification of Green Mark, Building Construction Authority - Singapore. Sedona Hotel's new portion, Inya Wing has complied with Green Mark's certification requirements to specify as a green building and Junction City shopping mall is attempting to achieve green certification from BCA, Singapore, especially for the hotel tower, office tower, and shopping mall phase 1 [2]. Ten hotels in Myanmar have been selected to confer ASEAN green hotel award which is honored to hotels in the ASEAN region annually. This prize has been awarded for resorts and hotels which meet 
the requirements of Green ASEAN hotel standard including 11 criteria at the ASEAN Tourism Forum 2018 observed in Chiang Mai, Thailand [16].

\section{Comparison of Seven Green Building Rating Tools}

Green building rating tools have been introduced since environmental conservation reaches at the center of global concern [17]. In recent years, green building rating tools have been applied to promote the sustainability of the built environment [18]. Rating tools can be defined as standards to assess the building performance that corresponds with a set of assessment criteria [17]. Moreover, these can be used as a technology to promote the quality of building in the construction industry [19]. This paper considers seven widely recognized green building rating systems namely LEED (Leadership in Energy and Environmental Design, United States), BREEAM (BRE Environmental Assessment Method, United Kingdom), BCA Green Mark (Singapore), Green Star (Australia), Three Star - Chinese Green Building Label-3, CASBEE (Comprehensive Assessment System for Built Environment Efficiency, Japan), and HQE (High-Quality Environmental Standard, France).

\subsection{Overview of Assessment Tools}

\subsubsection{Leadership in Energy and Environmental Design (LEED)}

LEED was established by the US Green Building Council (USGBC) and Green Building Certification Institute (GBCI) in the year 2000. LEED is a type of non-profit organization and has eight criteria for assessment such as location and transportation, sustainable sites, water efficiency, energy and atmosphere, materials and resources, indoor environmental quality, innovation, and regional priority. The certification level is defined as four stages Platinum (80-100 points), Gold (60-79 points), Silver (50-59 points), and Certified (40-49 points). LEED is applied for building design and construction, interior design and construction, building operations and maintenance, homes, and neighborhood development (plan and build project) of commercial buildings, schools, healthcare, and single and multifamily homes [20,21].

\subsubsection{BRE Environmental Assessment Method (BREEAM)}

BREEAM was founded by the UK Government, Building Research Establishment and BRE Trust in 1990 and stands as a non-profit organization. There are ten green building criteria in BREEAM - management, transport, land use and ecology, water, energy, materials, health and wellbeing, innovation, waste and pollution. The score level is classified as Outstanding $\geq 85+$, Excellent $\geq 70$, Very Good $\geq 55$, Good $\geq 45$, Pass $\geq 30$, and Unclassified $<30$. Office, retail, industrial, data centers, education, healthcare, residential, mixed-use, other buildings, and courts and prisons are certified by BREEAM [20;22].

\subsubsection{Green Star}

The Green Star was launched in Australia by Green Building Council Australia (GBCA) in 2003 and it is a type of non-profit organization. Green star divides criteria as nine categories - management, transport, land use and ecology, water, energy, material, indoor environment quality, innovation, and emissions. The point scale is defined as Assessed/Zero Star (less than 10\%), Minimum Practice/One Star (10\%-19\%), Average Practice/Two Star (20\%-29\%), Good Practice/Three Star (30\%-44\%), Australian Best Practice/Four Star (45\%- 
59\%), Australian Excellence/Five Star (60\%-74\%), and World Leadership/Six Star (75\%+). Green Star is responsible for communities and precincts, design and construction of new buildings, major refurbishments, new interior fit-outs, public buildings, and sustainable building operations $[20,23]$.

\subsubsection{Three Star, Chinese Green Building Label-3}

Three-star, introduced by Ministry of Housing and Urban-Rural Development (MOHURD) in China in 2006, includes seven main criteria namely operational management, land saving, and outdoor environment, water-saving and water resources utilization, energy-saving and utilization, materials saving and materials resources utilization, indoor environmental quality, and preferences. Three-star is applicable for public and residential buildings. The score level is based on 3-Star (80), 2-Star (60), and 1-Star (50) for green building certification [20].

\subsubsection{Comprehensive Assessment System for Built Environment Efficiency (CASBEE)}

CASBEE is developed by Japan's Ministry of Land, Infrastructure, Transport, and Tourism (MLIT), and Institute for Built Environment and Energy Conservation (IBEC) in 2001. CASBEE covers all residential and non- residential buildings. The assessment criteria are divided into two main categories - Q (built environment quality) which consists of quality of service, outdoor environment on-site, and indoor environment, and L (Build load) which consists of resources and materials, energy, and off-site environment. The point system is designed by the result of BEE (building environmental efficiency) from Q for building performance divided by $\mathrm{L}$ for environmental impact. The certification levels of CASBEE depending on $\mathrm{BEE}$ are Superior: $\mathrm{S}(\mathrm{BEE} \geq 3.0$ and $\mathrm{Q} \geq 50$ ), Very good: $\mathrm{A}$ ( $\mathrm{BEE} \geq 1.5)$, Good: $\mathrm{B}+(\mathrm{BEE} \geq 1)$, Slightly poor: $\mathrm{B}-(\mathrm{BEE} \geq 0.5)$, and Poor: $\mathrm{C}(\mathrm{BEE}<0.5)[20,24]$.

\subsubsection{High-Quality Environmental Standard (HQE)}

HQE is a green building rating tool in France and it was initiated by HQE Association for France Scheme, and supported by Cerway for International Scheme in 2012. HQE is a type of non-profit organization and is based on eight criteria for certification such as maintenance, site, water, energy, components, indoor environmental quality, waste, and worksite. HQE enables residential, non-residential, and detached houses. Credit awards for buildings are HQE PASS (between 1 and 4 stars), HQE GOOD (between 5 and 8 stars), HQE VERY GOOD (between 9 and 11 stars), HQE EXCELLENT (12 stars and more with at least 3 stars for "energy" category) [20, 25].

\subsection{Similarities and Differences between Criteria and Categories}

By comparison of the above seven existing rating systems, BREEAM, the first certification system, proposed rating categories in 1990, which have been adopted by other rating systems using various alternative terminology. For example, 'Land Use and Ecology' in BREEAM is referred to as 'Sustainable Sites' in LEED, 'Climatic Responsive Design' in Green Mark, 'Land Saving and Outdoor Environment' in Three Star, 'Outdoor Environment on Site' in CASBEE and 'Site' in HQE. Similarly, 'Indoor Environmental Quality' from most tools 
can be seen in BREEAM and Green Mark in different names such as 'Health and Wellbeing' and 'Smart and Health Building'.

LEED provides 8 categories including 'Location and Transportation', 'Sustainable sites', 'Water Efficiency', 'Energy and Atmosphere', 'Materials and Resources', 'Indoor Environmental Quality', and 'Regional Priority' for green building assessment process in which 'Regional Priority' criteria is only standardized for LEED and not in other remaining 6 rating systems. BREEAM, Green Star, Three Star, CASBEE, and HQE evaluate for advancing the management procedure in all phases of the project with the green building objectives whereas LEED and Green Mark are lack of consideration of the 'Management' category in their standards. 'Innovation' is an applicable category in LEED, BREEAM, and Green Star while 'Pollution' in BREEAM and Green Star, and 'Waste' in BREEAM and HQE are prioritized for considering the contamination. Five common criteria which are inserted as the basic need of every certification system in all selected 7 green building rating tools are as follows.

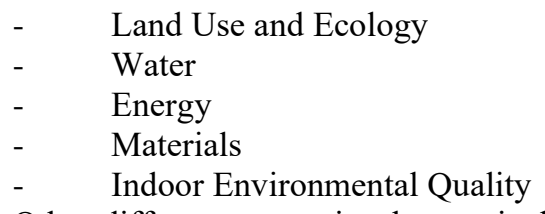

Other different categories that are included in only some rating tools among the considered seven tools are as follows.

$\begin{array}{ll}\text { - } & \text { Management } \\ \text { - } & \text { Transportation } \\ \text { - } & \text { Waste } \\ \text { - } & \text { Pollution } \\ \text { - } & \text { Regional Priority } \\ \text { - } & \text { Advanced Green Effort }\end{array}$

\subsection{Comparison of Points and Credits}

Almost all rating tools, except CASBEE which is emerged from Japan, designate score level upon criteria by percentage or points to determine the building with green standards. In the CASBEE scoring system, Building Environmental Efficiency (BEE) is an assessment specification which is attained from Build Environment Quality, Q (performance of a building) is divided by Built Load, L (Building's adverse impact on the environment). A building is deliberated more sustainable when the slope is steeper in the graph with a higher value of $Q$ and lower value of L. Among the nominated seven rating tools compared in Table 1, 'Management' is assigned as one criterion in BREEAM, Green Star, Three Star, and HQE with the intention of promoting management system of the whole project performance as design, construction, and maintenance in accordance with objectives of green buildings. LEED from the United States favors 'Energy' by means of reducing energy usage and applying renewable energy in a building for mitigating greenhouse gas emissions in the environment, as the main criteria with $30 \%$ of the total score. Likewise, BREEAM, Green Star, and Three Star chose 'Energy' as the most effective category with a score of $20 \%, 20 \%$, and $18 \%$ respectively. It is noticeable that 'Indoor Environmental Quality' criteria (improving occupants' health and comfort living) in HQE has the highest weighting of $43 \%$. 'Climatic Responsive Design'(building and environment design for climate resilience, the purpose of site selection, and preservation of existing green space and natural characteristics) is the focus of Green Mark as represented by the score weighting of $25 \%$. 
Despite other rating systems defines 'Land Use and Ecology', Green Mark names 'Climatic Responsive Design' as climate change action is also considered in this criterion. 'Transport' (reducing carbon footprint from vehicles near the site) is stated as $15 \%$ in LEED, $8 \%$ in BREEAM and 9\% in Green Star whereas 'Waste' and 'Pollution' are described $6 \%$ and $9 \%$ in BREEAM and, $2 \%$ and $6 \%$ in HQE respectively. To sum up, 'Energy' is the most powerful criteria except HQE and Green Mark. 'Materials' (choosing green products for preventing natural resources depletion and minimizing environmental impact with less embodied energy) and 'Water' (water efficiency and wastewater management) are vital elements after 'Energy' and 'Indoor Environmental Quality'.

Table 1. Points Percentage of Selected Green Building Rating Systems

\begin{tabular}{lcccccc} 
Criteria & LEED & BREEAM & $\begin{array}{c}\text { Green } \\
\text { M ark }\end{array}$ & $\begin{array}{c}\text { Green } \\
\text { Star }\end{array}$ & $\begin{array}{c}\text { Three } \\
\text { Star }\end{array}$ & HQE \\
\hline Energy & $30 \%$ & $20 \%$ & $18 \%$ & $20 \%$ & $18 \%$ & $14 \%$ \\
$\begin{array}{l}\text { Indoor Environmental } \\
\text { Quality }\end{array}$ & $15 \%$ & $14 \%$ & $18 \%$ & $15 \%$ & $17 \%$ & $43 \%$ \\
M aterials & $12 \%$ & $9 \%$ & $13 \%$ & $13 \%$ & $16 \%$ & $8 \%$ \\
W ater & $10 \%$ & $6 \%$ & $9 \%$ & $11 \%$ & $17 \%$ & $8 \%$ \\
Land U se and E cology & $9 \%$ & $7 \%$ & $25 \%$ & $5 \%$ & $17 \%$ & $13 \%$ \\
$\begin{array}{l}\text { Transport } \\
\text { M anagement }\end{array}$ & $15 \%$ & $8 \%$ & & $9 \%$ & & \\
Innovation & & $14 \%$ & & $13 \%$ & $15 \%$ & $6 \%$ \\
W aste & $5 \%$ & $7 \%$ & & $9 \%$ & & \\
Pollution & & $6 \%$ & $3 \%$ & & & $2 \%$ \\
Regional Priority & & $9 \%$ & & $5 \%$ & & \\
A dvanced Green Efforts & & & & & &
\end{tabular}

(Note: CASBEE is excluded due to having different assessment method from other systems)

\section{Developing a Green Building Rating System for Myanmar: Future Work}

Green building rating tools are widely used not only in developed countries but also in various ASEAN countries to assess the environmental performance of a building. Myanmar has taken an initial step to execute its own rating system as a developing country in order to move forward. Based on the comparison of the Green Building Rating systems, it can be seen that the similar criteria that have been adopted across all the systems fall in the areas of Energy, Indoor Environmental Quality, Materials, Water, and Land Use and Ecology. These areas are in line with the existing criteria proposed by Myanmar's Green Building Committee, including "Energy", "Water", "Human Comfort and Health", and "Environmental Impact". Even though it is easy to adopt rating systems from one country to another, one thing needed to be considered is that they are suitable or not with the local climate, economy, technology advancement, construction market, and geographical 
conditions. Therefore, this study aims to investigate in the future the Junction City, Yangon and Sedona Hotel, Inya Win which are certified as green buildings by Green Mark, Singapore, as case studies. The collection of engineering drawings and documents about these buildings and site observations will be carried out as the first step, and followed by questionnaires and interviews of representative persons (e.g. architects, civil engineers, M\&E engineers, managers, and developers) who participated in these projects during design, and construction period. Questionnaires are divided into three parts; firstly, technical questions from site observation to architects and engineers which will be beneficial to technical requirements of Myanmar's green building rating system implementation. The future study will also examine the adoption of Myanmar's technical sustainability standards from Singapore, as reflected in the Myanmar National Building Code 2016. For the second component, challenges, and difficulties while attempting to achieve a green mark certificate from BCA, Singapore will be examined in order to assist the assessment process of developing Myanmar's rating system. Finally, interviews for the market condition of green materials and products in Myanmar, and how much degree of knowledge and experience about green building objectives and standards the experts have, will be conducted for the case of awareness about green buildings in Myanmar. The desired outcomes will support partly Green Building Committee - BEI (Myanmar) to adopt some technical standards from Green Mark, Singapore and to improve green building chapter in MNBC 2016 for the development of Myanmar's green building rating system.

\section{Conclusions and Recommendation}

By consideration of green building requirements and the current green movement in Myanmar, the certification system is fundamental to regulate the green building practice. Besides, rating tools can provide awareness for green environment and sustainable development. As a responsibility of the government, the environmentally friendly building design to reduce greenhouse gas emissions and the waste pollution should be taken into consideration in public housing projects that will be implemented for the increased population. To be successful in green building development, understanding about the green building objectives and unity of key players from all related fields are required. Hence, it is time to share relevant information and knowledge about sustainable building practices between professionals and the government for public awareness. Moreover, the comparison of seven green building rating systems demonstrates that energy efficiency is the most common criterion with the highest score points for assessment, followed by the aspects of Land Use and Ecology, Water, Materials and Indoor Environmental Quality. Although these common criteria have been, to some extent, considered in the current Myanmar National Building Code, the study concluded that to further develop a green building rating system for Myanmar, the remaining criteria should be considered with respect to the conditions that are domestic to the country, basing on the experience gained from the construction of buildings that have already been certified as green. Further understanding of the challenges and opportunities observed through these buildings will be the aim of future research. 


\section{References}

1. U.T. A ung, Country analysis paper on 3R practice in Myanmar, Fourth Regional 3R Forum in A sia, Hanoi, V ietnam (2013)

2. Y.T. Tin, Construction sector going green, The Myanmar Times (2007), https://www.mmtimes.com/opinion/25803-construction-sector-going-green.html

3. MCEA presentation, Fulfilling Myanmar's affordable housing requirement: implementation plans and status, M yanmar infrastructure summit (2018)

4. S. M ilad, The investigation of the barriers in developing green building in Malaysia, Modern Applied Science 7(2): 1913-1852 (2013)

5. Oxford Business Group, The Report: Myanmar (2017), https://oxfordbusinessgroup.com

6. R. Vakulchuk et al., Myanmar's attractiveness for investment in the energy sector, a comparative international perspective, Myanmar Institute of Strategic and International Studies (2017)

7. Y.L. Zay, Underground water demand could weaken buildings, The M yanmar Times (2015), https://www.mmtimes.com/business/16248-underground-water-demand-couldweaken-buildings.html.

8. Burma -Environmental Technology (2017), https://www .export.gov/ article?id=B urmaEnvironmental-Technology.

9. P.J.D. Gamaralalage, M. Hengesbaugh, O. M ay Tin Hlaing, Quick study on waste management in Myanmar, current situation and key challenges, Institute for Global Environmental Strategies (2016)

10. A. M ardiana, S.B. Riffat, B uilding energy consumption and carbon dioxide emissions: threat to climate change, Journal of Earth Science \& Climatic Change, S3:001 (2015)

11. A. Fatima, Climate change is undermining sustainable development in M yanmar. Here is what can be done about it, https://www.devex.com/news/climate-change-isundermining-sustainable-devel opment-in-myanmar-here-is-what-can-be-done-about-it89885

12. L.L.A. Mya, Improving solid waste management in urban Myanmar - A study from Yango, Summary of EEPSEA Research Report N 0. 2016-SRG 7 (2016)

13. N. M ahesh, K.P. Dhananjay, Solid waste management in green building (2016)

14. Development of Building Engineering Institute (BEI), Myanmar Engineering Society presentation, 1 November 2014, (2014)

15. GBC-BEI M yanmar, M yanmar National Building Code 2016: Part two - architecture and urban design, section 2.12 architecture for energy efficiency and green (2016)

16. L.M. Shwe, $10 \mathrm{M}$ yanmar hotels win A SEA N tourism awards, M yanmar B usiness Today 6(4) (2018), https://www.mmbiztoday.com/articles/10-myanmar-hotels-win-aseantourism-awards.

17. L. A bdullah, N. Jumadi, R. Sabu, H. A rshad, F.F. M ohd Fawzy, A ssessment criteria on sustainable rating tools used in A sian countries, Jurnal Teknologi (2015)

18. E.C. M pakati-Gama, S.C. Wamuziri, B. Sloan, Green building challenges: evaluating the operation of adopted building assessment tools - case study, Procs $28^{\text {th }}$ Annual ARCOM Conference, 3-5 September 2012, Edinburgh, UK: 1257-1267 (2012)

19. Z.M. Darus, N.A. Hashim, E. Salleh, L.C. Haw, A.K.A. Rashid, S.N.A. Manan, Development of rating system for sustainable building in Malaysia, WSEAS Transactions on Environment and Development 5(3) (2009)

20. A Review of Seven Regional and International Green Building Certification System, Final Draft. W inrock International Institute for A gricultural Development, Hanoi (2014)

21. LEED 4 for $B D+C$ : new construction and major renovation, project checklist (2018), https://new.usgbc.org/. 
22. BREEAM international new construction 2016 technical manual (2016), https://www.breeam.com/.

23. Green Star-design \& as built scorecard V1.2 update 1/07/2017, Green B uilding Council A ustralia (2017), https://new.gbca.org.au/

24. CASBEE for new construction (2010 Edition), score sheet (2010), http://www.ibec.or.jp/CA SBEE/english/.

25. HQE assessment scheme, evaluation tool EBR (2014), http://www.behqe.com/ 